\title{
MEANING-MAKING IN TECHNOLOGY-ENHANCED LEARNING ACTIVITIES: A COMPOSITE PERSPECTIVE OF TECHNOLOGIES AND THEIR PROPERTIES AND USERS' REPRESENTATIONS
}

\author{
Karoline Schnaider, Limin Gu \\ Umeå University (SWEDEN)
}

\begin{abstract}
Technology use in school settings tends to look at various technologies solely as mediators for production and work, rather than to relate them to the patterns of thinking and learning. Some technologies and representations are more overrepresented than others, which signals a more monotonous use [22]. However, recent research indicates that meaning-making (actions and signmaking/learning) in connection with technology use is characterized by a higher level of variety and multiplicity across technologies and their properties and users [9], [13], [14], [22]. There is a need to explore and gain insights into how multimodal technology use can be understood and supported from a more comprehensive perspective. This study aims to examine the use of technologies (hardware and software in combination) in students' meaning-making activities in Swedish schools from a multimodal layer (ML) approach [22]. The research questions are the following: what functional and semiotic properties of the technologies are prompted and drawn upon in use; how are transitions made between technologies, their properties, and users; and what modes of representations are made by individuals in relation to the actions and sign-making activities with different configurations of technologies?
\end{abstract}

The ML framework was used as a vehicle for data gathering and analysis from its five components: technologies, technologies' functional properties, technologies' semiotic properties, modes of representation, and activities. Empirical data consisted of 8 hours of classroom video recordings and observations on students' use of technologies in their learning activities, and 6 hours of interviews with the students were observed. All data were transcribed into texts-for instance by using word processing software and the video annotation software Transana-for subsequent quantitative content analysis. The layers were used as the first coding categories in processing the transcriptions and as variables in the analysis. The second step of coding was based on keywords (the values - subcategories to the layers) by using the software nCoder. Finally, the program Epistemic Network Analysis (ENA) was used to visualize the connections between the layers [44], [45].

The results from the ENA, as expected, are that some functional properties were more frequently used at specific mediating levels with the use of certain technology combinations and had stronger connections to modes of representation and activities than other properties had. Moreover, some functional properties tended to remain at the same mediating level between technologies, while others were entirely altered or even eliminated. The investigations also showed that some categories of technologies and properties were more frequently drawn upon, reflected in the users' modes of representations. In some activities and combinations of technologies, the transitions in the various functions to the semiotic properties were more complicated and had little influence on individuals' meaning-making, as shown in weak ENA connections. These findings have implications for technology design and implementation by clarifying how technologies benefit particular actions and sign-making activities.

Keywords: Technology, hardware, software, function, properties, semiotic, multimodal, layers, representations, meaning-making, action, sign-making, activity.

\section{INTRODUCTION}

Recent social semiotic multimodal research has pinpointed that specific components are essential to acknowledge in technology use. Specifically, this stream of research requests a take on multimodality that recognizes how users combine different technologies and draw upon their properties to represent meaning variously [1]. For instance, Jewitt's [2] work on software shows that the distribution media identify the transitions between sign systems (e.g., a text that gets transduced into visual modalities in the switch from analogue to digital technology, with impingement on students' meaning-making activities). Also, Jewitt's [3] research on the use of hardware explores how, e.g., the screen with its specific function of framing affected the visualization fed into writing, layout, and composition. Roberts, 
Djonov, and Torr [4] and Norris [5] identified the need for recognizing the meaning potentials that both hardware and software help organize by varying emphases and how their designed physical and symbolic features are involved in and impose on students' activities in different ways-for instance, the size of computer monitors to be displayed in relation to the software application, which constrains some activities and affords others and contributes to different modes of representation. Djonov and van Leeuwen [6] found that various properties of the technologies-for instance, the template-guided the composition of the content to make meaning in presenting information through a PowerPoint (PPT) design. Other research has similarly emphasized digital software in relation to the sign systems in the interface and how different interpretations of them have afforded various actions and modes of representation and use [7-13]. Vigild Poulsen [14] and Vigild Poulsen and Kvåle [15] have made significant contributions to understanding the relationships between technologies' technical functions and their visual functional properties in their explorations of, for instance, the software application Instagram. Moreover, Adami [16] made links between functional properties and physical and symbolic features related to hardware smartphones and the fluidity between actions facilitated by design. Keys in different colors and screens of different sizes were connected to various functions between smartphone models and activated unique usage and modes of representations in navigating the phone. Similarly, Zhao and Zappavigna [17] discovered that the distance enabled by the function of a smartphone selfie stick to take pictures in a specific proximity, combined with the Instagram app's editing function, allowed for an image to be communicated through a social media platform. More specifically, in relation to functions, McDonald, Le, Higgins, and Podmore [18] and the Swedish National Agency For Education [19] adopted the Wartofskyan artifact taxonomy [20] to exemplify use related to functions' various affordances depending on their involvement in mediating actions. Functions are not stable units, at least not as shown by Alnervik's [21] research on the use of materials for student assessment and documentation in preschool and how they took on different mediating levels across processes, users, needs, and activities. Alnervik pointed to the transitions between functions in the use of a question template. The template was functioning on a primary mediating level since it made the work effective. Simultaneously, it was functioning on a secondary mediating level as it helped organize the work. By organization, the template facilitated reflection and conversations about practices. It allowed teachers to share knowledge that in turn formed a basis for pedagogical development. Thus, the template also had a tertiary meditating level.

This study aims to examine technologies' use (hardware and software in combination) in students' meaning-making activities in Swedish schools through a multimodal layer (ML) approach [22]. This approach embraces the components defined by previous research, focusing on technologies, their properties that move across different configurations of technologies, and users' needs, and transforms various actions and sign-making activities into different modes of representation. The research questions are as follows: what functional and semiotic properties of the technologies are prompted and drawn upon in use; how are transitions made between technologies, their properties, and users; and what modes of representations are made by individuals in relation to the actions and sign-making activities with different configurations of technologies?

\subsection{Theoretical framing}

Multimodal layers (MLs) relate to technology-enhanced learning activities by focusing on the connections between the nature of the technologies and students' meaning-making with equal emphasis, and they originate in ideas about representations. Representations in whatever shape are the basic units of human historical, cultural, and social production of meaning into form. Representations denote a circular and intimate relationship between the external world created, manifested, and simultaneously perceived and interpreted by humans and the inner mental processes that produce and establish new representations internally or externally from the given input [20], [23], [24], [25]. MLs are specifically centered around technologies and sign systems as examples of essential representations managed daily by humans. MLs set out to unite mediators (technologies and sign systems) with mediation (the cognitive processes) and are associated with the dialectical and non-dualistic relations between technologies and their properties (digital visual user interfaces, or DVUIs) and humans' meaning-making through five components: technologies, technologies' functional and semiotic properties, modes of representation, and activities.

As hardware and software technologies interrelate from their technical assets, they jointly make up a complex system for the user to perceive, interpret, and give meaning [26]. For instance, both hardware and software have inherent physical and symbolic properties that vary through visualization of the technologies in different configurations jointly prompted through DVUls. The concept of DVUls has essential references to humans' perception - the visual and the semiotic - as properties change with 
combinations of hardware and software technologies that render different meaning potentials and contribute to various affordances. Technologies' functional properties are related to the physical and symbolic sign systems of the DVUls and the technical functionalities. When perceived and interpreted, they evoke different actions related to the users' knowledge about the technical functionalities, and they manifest the relationship between the design and intentional human actions [27], [28]. The connections between form and meaning visualized in DVUls in functional properties are related to the embodiment of a function (the signified) of an expression (the signifier). Thus, the technical functionality is linked to hardware and the system and application software, whereas the DVUls govern the fashion in which the DVUIs are performed and subsequently used [29]. The functional properties are involved in orienting human actions through primary, secondary, and tertiary mediating levels [20], [25]. The Wartofsky taxonomy makes a vital proposal to understand how technologies connect to cognitive processing and how they work on different levels of mediation in relation to actions.

Technologies' functional properties are closely related to the technologies' semiotic properties-for example, the zoom function on a tablet to visualize content. The functional property can be a tertiary mediator in the action of displaying something while being semiotic in how it modifies the meaning of what is displayed by changing its size, and therefore it becomes meaningful (semiotic) for use in discussions around an image. Although functional and semiotic properties are intimately linked in cognitive processing, there is a subtle difference between them. Functional properties are drawn upon in different levels of mediation and help accomplish different actions [20], [25], while semiotic properties are used and shaped at the intersection of different functions and the available sign systems to be used in students' consumption and production activities in different modes of representation. Meaning-making comes about when DVUls or humans act as prompters and an input is perceived, interpreted, and transformed either as inward meaning or outward materialization into actions or sign-making activities [23], [24], [30]. It is a circular activity between the world and humans' cognitive processing [24], and the actions and sign-making activities become visible in modes of representation [23]. Modes of representation are the result of the shaping and reshaping of the available sign systems that alter them in the process of becoming the most apt signifier for the new thing signified [23], [30], [31], [32]. The modes of representation adhere to what is known about the meaning potentials and affordances of the culturally available sign systems and what students assume are feasible representations to convey in a specific frame of reference [30]. Activities frame the socially and contemporarily accepted technologies and sign systems and the produced knowledge in a particular context at a specific moment in time, which upholds the current discourses within that domain [33], [34]. The school maintains and newly produces activities that adhere to such established principles and are ultimately framed by a specific setup of, for instance, a subject and individual or collaborative activities, learning design ideas, etc. The co-design activity is equal to the dynamic process of sign-making that happens when the participants mediate their responses to what is prompted to them from the specific configurations of subjects, technologies, and other participants and how interpretation and communication are shared between such units [32], [35], [36]. In summary, the ML framework ascribes multimodal principles and offers an analytical lens to understand and support the multiple ways that meaning is shaped in technologyenhanced learning activities for students in the school. The components of the MLs appear within the semiotic system created by actors in learning settings with varying emphases.

\section{METHODOLOGY}

\subsection{Participants}

This paper set out to follow up on details and consider various components of the MLs to gain insight into how DVUls are jointly configured and how students mediate actions and create meaning in use. The central idea was to describe, explain and understand the phenomena from small sample sizes and the situated data, making it possible to detect variations, connections, or more frequent occurrences in use by applying multimodal layers. Due to the comprehensiveness of the multimodal layers approach, a delineation of the number of participants had to be made. A meticulous selection of students as technology users was therefore made necessary by adopting a purposive selection [37]. Three students were selected according to the following sampling criteria: 
Table 1: Student sampling criteria

\begin{tabular}{|l|l|}
\hline \multicolumn{1}{|c|}{ Category } & \multicolumn{1}{c|}{ Inclusion } \\
\hline Students: & $\begin{array}{l}\text { Students who are experienced technology users (i.e., who use the assigned digital hardware daily in } \\
\text { learning activities) why sampling undertaken in technology-dense (1:1) practices was essential. }\end{array}$ \\
\hline Demography: & $\begin{array}{l}\text { Three schools of different sizes from different areas were selected, with the greatest interest being } \\
\text { the variety of digital devices used. }\end{array}$ \\
\hline $\begin{array}{l}\text { Classrooms } \\
\text { and grades: }\end{array}$ & $\begin{array}{l}\text { Students from year five were selected on the basis of the environments in which students and } \\
\text { teachers continuously worked together, to explore the layer of "activities" linked to individual or social } \\
\text { activities and design of subjects and learning. }\end{array}$ \\
\hline Technologies: & $\begin{array}{l}\text { The three students represented the use of the most common mobile devices (i.e., laptops, tablets, } \\
\text { and smartphones, separately). The schools provided hardware and software technologies. }\end{array}$ \\
\hline Activities: & $\begin{array}{l}\text { As part of the activity portfolio, a broad representation of subjects was included. Lessons were } \\
\text { chosen where students would be active in using technology during most of the class, including } \\
\text { collaboration and individual work. }\end{array}$ \\
\hline
\end{tabular}

\subsection{Data collection}

Data on students' use of technologies was gathered through video recordings, observations, and interviews. The guiding principles for data collection are found in Table 2 below.

Table 2: The focus of data collection based on multimodal layers

\begin{tabular}{|c|c|c|c|}
\hline Layer: & Definition: & Focus: & Examples of data (also used as keywords): \\
\hline Technologies & $\begin{array}{l}\text { Hardware and } \\
\text { software }\end{array}$ & $\begin{array}{l}\text { All digital hardware and } \\
\text { software devices used } \\
\text { in learning design and } \\
\text { meaning-making } \\
\text { activities. }\end{array}$ & $\begin{array}{l}\text { Computers, laptops, tablets, smartphones, and digital } \\
\text { learning material (publisher-made), online software, } \\
\text { social media, documents, programs et cetera. }\end{array}$ \\
\hline $\begin{array}{l}\text { Technologies' } \\
\text { functional } \\
\text { properties }\end{array}$ & $\begin{array}{l}\text { Primary, secondary, } \\
\text { and tertiary functional } \\
\text { properties in physical } \\
\text { and symbolic sign } \\
\text { systems. }\end{array}$ & $\begin{array}{l}\text { Goal-related actions on } \\
\text { different levels of } \\
\text { mediation with DVUIs } \\
\text { related to the functions } \\
\text { used. }\end{array}$ & $\begin{array}{l}\text { Projecting (with a projector or screen), } \\
\text { navigating/scrolling with a cursor/mouse, editing images } \\
\text { using filters, hiding and revealing content, applying } \\
\text { effects (by speeding up/slowing down), changing } \\
\text { typographic style by using toolbar. }\end{array}$ \\
\hline $\begin{array}{l}\text { Technologies' } \\
\text { semiotic } \\
\text { properties }\end{array}$ & $\begin{array}{l}\text { The sign systems } \\
\text { available for use in the } \\
\text { technologies used in } \\
\text { sign-making activities. }\end{array}$ & $\begin{array}{l}\text { The use of the } \\
\text { technologies' functional } \\
\text { and semiotic properties } \\
\text { and the available } \\
\text { inherent sign systems } \\
\text { drawn upon in modes } \\
\text { of representation. }\end{array}$ & $\begin{array}{l}\text { Color, background, font, typographic elements, graphics, } \\
\text { space, layout, shape/size. }\end{array}$ \\
\hline \multirow[t]{7}{*}{$\begin{array}{l}\text { Modes of } \\
\text { representation }\end{array}$} & \multirow{7}{*}{$\begin{array}{l}\text { People create } \\
\text { meaning in different } \\
\text { actions and sign- } \\
\text { making activities [20], } \\
\text { [30]. }\end{array}$} & \multirow{7}{*}{$\begin{array}{l}\text { Meaning-making made } \\
\text { by students embodied } \\
\text { in different modes of } \\
\text { representations. }\end{array}$} & $\begin{array}{l}\text { Multimodal: combination of, e.g., auditory-linguistic- } \\
\text { visual-gestures modalities. }\end{array}$ \\
\hline & & & Auditory: speech, dialogues, discussions, music, sound. \\
\hline & & & Linguistic: writing, reading, word processing. \\
\hline & & & Gaze: looking, directing attention. \\
\hline & & & $\begin{array}{l}\text { Gestures: pointing, nodding, gesticulating, indicating with } \\
\text { hands. }\end{array}$ \\
\hline & & & Visual: drawings, images and moving images. \\
\hline & & & Touch: touching the screen using fingers. \\
\hline Activities & $\begin{array}{l}\text { The framing provided } \\
\text { by the subject, the } \\
\text { assignments, and the } \\
\text { social configuration of } \\
\text { teachers and students } \\
\text { in learning design and } \\
\text { co-design. }\end{array}$ & $\begin{array}{l}\text { The subject, the } \\
\text { discourses, the shared } \\
\text { actions and sign- } \\
\text { making activities. }\end{array}$ & $\begin{array}{l}\text { Subject-specific areas and assignments, individual work, } \\
\text { collaboration, interactions around learner content } \\
\text { between a teacher and student, presentation, } \\
\text { demonstration of teaching content. }\end{array}$ \\
\hline
\end{tabular}


Although the ML components were all deemed necessary in the study, it was still the case that some features appeared as foregrounded and others as more backgrounded within a specific contextual framing in relation to activities performed [38]. To be able to study these relations, Bezemer and Kress [30], Kress [23], and Norris [39] claimed that the amount of attention directed by the informants proved what captured interest and commitment and was more densely configured and essential at that time. The informants' awareness became visible in their actions and sign-making activities with the DVUls, turning into modes of representation (gaze, gestures, etc.).

\subsubsection{Video recordings}

Two cameras were used; one focused on the informants' activities, and one gave a close-up perspective on the technology used and the informants' actions on and around the screen. The data collection method required careful initial planning of the actors' position in relation to the camera angle and what direction the camera needed to take to capture different aspects of technology use [35], [40], [41]. The students' activities were recorded with two cameras during approximately two lessons of 40 minutes each (i.e., two lessons $x 40$ minutes $x$ two cameras $x$ three informants). The camera time for recorded data from two cameras and all informants totaled approximately 480 minutes (8h).

\subsubsection{Observations}

During the video recordings, systematic observations were also carried out to clarify and add information to the video recordings. Observation schedules were structured on the basis of the multimodal layers. The purpose of the observations was to clarify relationships in the subsequent video annotation and strengthen the reliability and the researcher's interpretations. The observers also paid attention to the students' interactions with others.

\subsubsection{Video elicitation interviews}

Semi-structured video elicitation interviews with each observed student were conducted on the basis of selected video sequences and a question guide. The interviews set out to clarify the use of technologies through the informants' descriptions. Thus, video sequences intermixed with the interview questions were used to reconstruct past thinking and enhance post-activity narratives [41]. Video sequences were carefully selected before the interviews, focusing on how the students illustrated different aspects of technology use. The interviews were conducted in the informants' respective school environments; they were recorded with audio recording equipment and varied in time between approximately 1.5 and 2 hours (4.5-6 $\mathrm{h}$ in total).

\subsection{Data processing}

\subsubsection{Transcription, annotation, and segmentation}

The interviews and observations were transcribed into texts by the Word processing software. Video data is labor-intensive to examine and analyze, and instead of giving a partial account of recorded events by selecting sequences, the software Transana was used to annotate all the videos with descriptions of what happened during the classroom activities. The annotations were then exported as a text file. All texts were manually segmented into different sentences (lines and stanzas) [42] on the basis of how they described the different multimodal layers. All the texts were subsequently used in quantitative analysis.

\subsubsection{Quantitative data analysis}

According to Bell [43], quantitative content analysis allows for quantification of material and is an empirical procedure for quantifying reliable, explicitly defined categories (variables, i.e., ML). Content analysis adheres to patterns of representation in the media specified in the research by values, which in turn follow the theories underpinning the definitions to establish the coding procedures' reliability based on specific keywords [43]. The analysis proceeded from the hypothesis about the variables/values connected to the ML, in which some would vary, connect, or occur more commonly than others.

The variables represented the codes in the subsequent quantitative coding procedure. Through the software tool nCoder (http://www.n-coder.org/), the large number of data sets produced from the datagathering instruments could be included and coded efficiently at the same time as the reliability and validity of the codes could be verified, which would not be possible without that approach. Second, by coding the data in nCoder, the program Epistemic Network Analysis (see below) could be more easily 
used to analyze the variations, connections, and frequent occurrences between the MLs. The nCoder tool enables the inter-coder consistency and validity in the material between three raters (humanmachine/human) to be verified through the statistical measurements (the kappa $>0.9$, and the rho < 0.05) [42]. Keywords were rated on the basis of the texts' division into lines or combinations of lines (the segmentation) that corresponded to the meaning of the codes based on a binary present/not present decision [44]. It is crucial to connect codes to the overarching meaning under examination (the multimodal layers corresponding to technology-enhanced learning activities), in particular when the decision on the presence of a code is made from a single data line. It is often more feasible to code stanzas (collections of related lines), which eliminates the need to decide the presence of a code on each line in isolation. The ideas behind stanzas are about framing - a demarcation of social activities, perceptions, knowledge, and so forth against which events are merged into a coherent epistemic frame (the multimodal layers) [42]. Both stanzas and separate lines were used in segmenting the text into sentences. The program Epistemic Network Analysis (ENA) was used to identify the connections within the epistemic frame based on the coded stanzas/lines and by weighing the connections in relation to each other and visually presenting them in graphic ENA models. Through ENA, the ties between the multimodal layers and possible variations between them were made visible for interpretation [45] (see example in Fig. 1 and 2 below).

\section{EXPECTED RESULTS}

As the results have not yet been completely compiled and analyzed, the findings presented here are presumptive. The desire was to find variations between the different multimodal layers (MLs): for example, which functional and semiotic properties of the technologies are prompted and drawn upon in use, how transitions are made between technologies and their properties and users, and what modes of representations are made by individuals in relation to the actions and sign-making activities with different configurations of technologies. In other words, the focus was on relating the mediators to the mediation by using the ML to gain more comprehensive and detailed knowledge on technologyenhanced learning activities based on students' interactions with DVUls. Fig. 1 (subtraction network) and Fig. 2 (separated network) show examples of how an Epistemic Network Analysis (ENA) graph can visualize data from each user (hardware technology) on the basis of the coded data. The subtraction networks show each user's centroid in relation to the other users of a large number of networks, and the positions explain the variance between them. For instance, if centroids are non-overlapping/overlapping, there is an indication that differences/similarities exist between the five components of the ML. The separated networks on each user will be analyzed on the basis of the weighted connection (the thickness of the lines), which means that thicker lines indicate a stronger relationship between two codes and suggests that some MLs are more foregrounded in relation to each other and the user.

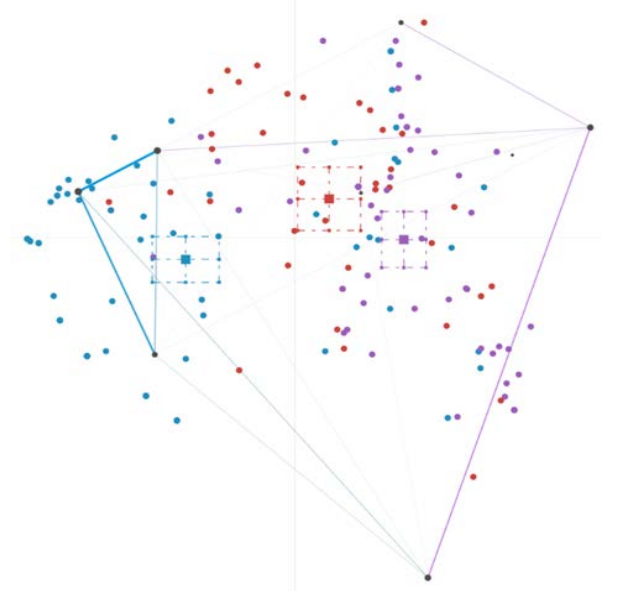

Figure 1: Example of ENA subtraction network 

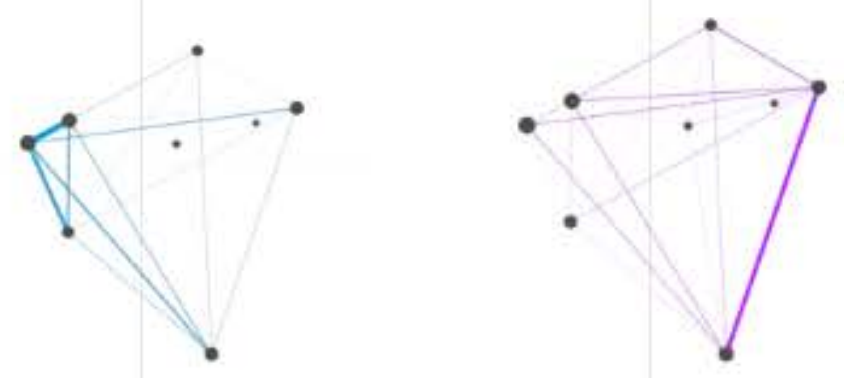

Figure 2: Example of ENA separated network for each user

The hypothesis was that some MLs should vary, connect, or occur more commonly than others. A possible finding in relation to this is that the $M L$ reappears with varying emphasis depending on, for example, the hardware, the activity — such as the school subject-and the user. However, more data is needed on different users to examine how the variations or relationships are related across users and layers as independent variables, by using other data-gathering methods such as multimodal learning analytics (MMLA) (as proposed by, e.g., [46], [47]. For example, how different configurations of software and hardware relate to and alter the visualizations of DVUls - and how that might affect perception and interpretation of the DVUls in different ways-is yet to be discovered by using, e.g., video- and eyetracking methods to distinguish differences in use depending on the hardware in relation to the use of the same software across multiple users.

Plausible findings are that specific hardware, such as smartphones, is included in more-interactive activities with peers and the teacher yet associated with an individual use facilitated by the proximity of each device and more volatile assignments. Moreover, the findings also suggest that certain hardware technologies, such as laptops and tablets, are more related to specific modes of representation, linguistic (writing texts) and auditory (speech), with regard to particular subjects such as language or social science. It is afforded by the hardware functional properties of a physical or symbolic keyboard to convey the primary action of writing while discussion learning content is displayed by the tertiary functional property of the screen.

Some functional properties appear to be more prominent, foregrounded, used with specific hardware such as laptops, and inexistent with other hardware, moving more thoroughly at a primary mediating level. One more evident variation is that the laptop facilitates more physical functional properties than the tablet and smartphone because of the latter examples' limited hardware accessories, making them more oriented towards symbolic functional properties promoted by the single screens. For example, laptops are often connected with accessing, navigating, and projecting, whereas on a tablet, for instance, it is more common to swipe, drag, and scroll on a primary mediating level. On the other hand, indications also exist that the functional property of hiding content in a document to organize the learning view on the screen is on a secondary mediating level related to a laptop, but on a tertiary mediating level in relation to a similar assignment with a shared-drive document to designate specific learning content with a tablet in collaborative activities. It is also interesting to note that the functional property of "highlight color for the text" in the toolbar is associated with a tertiary mediating level and the use of the semiotic properties of color and framing in relation to the production of text conferred in group discussions in all hardware technologies with regard to word processing documents facilitating those functions. In other words, specific semiotic properties occur more frequently in relation to all technologies and particular functions and modes of representation. Another example is the use of the most basic functional properties such as a toolbar to alter a font-a function that is frequently used across laptops, tablets, and smartphone technologies on a tertiary mediating level to change the semiotic property of the typography and is related to linguistic modes of representation in the production of different texts. Or there is the semiotic property of color, which is frequently used in, for instance, individual activities in math assignments in visual modes of representation in relation to tablets' and smartphones' drawing functional property.

\section{CONCLUSIONS}

By this brief exemplification of some of the relationships between the mediators and the mediation, it is evident that there are variations, connections, and frequent occurrences between the multimodal layers. These findings provide a detailed and comprehensive account of technology-enhanced learning 
activities in students' use of DVUls. This knowledge can contribute to a more effective implementation of technology-enhanced learning activities as well as to enhancing design thinking and technology design, by understanding of the nature of the technologies and how their meaning potentials and affordances are explicated in use. Knowledge about the fluctuations and transitions that exist between different technologies and their properties and what modes of representations are made by students in actions and sign-making activities with varying configurations of technologies can reinforce existing understandings that technologies must be designed and selected and implemented in learning settings based on the nature of the activity and the users' needs in relation to the technologies' affordances to convey specific meaning, rather than be based on other principles. Hence, detailed results such as those proposed here may highlight that different technologies are needed in learning settings due to their specific relationship to activities, users, and needs. Therefore, the results can feed into design principles and counteract today's implementation strategies of 1:1 devices that impose the same device on a whole population of students and lead to predominantly monotonous use.

\section{REFERENCES}

[1] C. Jewitt (Ed.), Routledge Handbook of Multimodal Analysis. London: Routledge, 2017.

[2] C. Jewitt, "The move from page to screen: the multimodal reshaping of school English," Visual Communication, vol. 1, no. 2, pp. 171-196, 2002.

[3] C. Jewitt, "Multimodality, reading and writing for the 21st Century," Discourse Studies in the Cultural Politics of Education, vol. 26, no. 3, pp. 315-331, 2005.

[4] S. Roberts, E. Djonov, and J. Torr, "The mouse is not a toy: young children's interactions with egames," Australian Journal of Language and Literacy, vol. 31, no. 3, pp. 242-259, 2008.

[5] S. Norris, "The implication of visual research for discourse analysis: transcription beyond language," Visual Communication, vol. 1, no. 1, pp. 97-121, 2002.

[6] E. Djonov and T. van Leeuwen, "Between the grid and composition: layout in PowerPoint's design and use," Semiotica, vol. 2013, no. 197, pp. 1-34, 2013.

[7] E. Adami, "What's in a click? A social semiotic framework for the multimodal analysis of website interactivity," Visual Communication, vol. 14, no. 2, pp. 133-153, 2014.

[8] E. Djonov and T. van Leeuwen, "The semiotics of texture: from tactile to visual," Visual Communication, vol. 10, no. 4, pp. 541-564, 2011.

[9] E. Djonov and T. van Leeuwen, "Social media as semiotic technology and social practice: the case of ResearchGate's design and its potential to transform social practice," Social Semiotics, vol. 28, no. 5, pp. 641-664, 2018.

[10] K. O'Halloran, A. Podlasov, A. Chua, and M. K. L. E., "Interactive software for multimodal analysis," Visual Communication, vol. 11, no. 3, pp. 363-381, 2012.

[11] K. O'Halloran, M. K. L. E., A. Podlasov, and S. Tan, "Multimodal digital semiotics: the interaction of language with other resources," Text \& Talk, vol. 33, no. 4-5, pp. 665-690, 2013.

[12] A. D. Sivle and P. H. Uppstad, "Reasons for relating representations when reading digital multimodal science information," Visual Communication, vol. 17, no. 3, pp. 313-336, 2018.

[13] S. Zhao and T. van Leeuwen, Understanding semiotic technology in university classrooms: a social semiotic approach to PowerPoint-assisted cultural studies lectures, Classroom Discourse, Vol. 5 No. 1, pp. 71-90, 2014.

[14] S. Vigild Poulsen, "Becoming a semiotic technology - a historical study of Instagram's tools for making and sharing photos and videos," Internet Histories, vol. 2, no. 1-2, pp. 121-139, 2018.

[15] S. Vigild Poulsen and G. Kvåle, "Studying social media as semiotic technology: a social semiotic multimodal framework," Social Semiotics, vol. 28, no. 5, pp. 700-717, 2018.

[16] E. Adami, "A social semiotic analysis of mobile devices: interrelations of technology and social habitus," in Mobile Learning (N. Pachler, B. Bachmair, and J. Cook, eds.), pp. 185-204, Boston: Springer, 2010.

[17] S. Zhao and M. Zappavigna, "Beyond the self: intersubjectivity and the social semiotic interpretation of the selfie," Australia New Media \& Society, vol. 20, no. 5, pp. 1735-1754, 2018. 
[18] G. McDonald, H. Le, J. Higgins, and V. Podmore, "Artifacts, Tools, and Classrooms," Mind, Culture, and Activity, vol. 12, no. 2, pp. 113-127, 2005.

[19] The Swedish National Agency for Education, Förskolans matematik. Att strukturera rummet. Accessed 11 July, 2019. Retrieved from https://larportalen.skolverket.se/\#/matematikexperten/

[20] M.W. Wartofsky, Perception, Representation, and the Forms of Action: Toward an Historical Epistemology. Dordrecht: Springer, 1973.

[21] K. Alnervik, "Systematic documentation: structures and tools in practice of communicative documentation," Contemporary Issues in Early Childhood, vol. 19, no. 1, pp. 72-84, 2018.

[22] K. Schnaider, L. Gu, and O. Rantatalo, "Understanding technology use through multimodal layers: a research review," International Journal of Information and Learning Technology, vol. 37, no. 5, pp. 375-387, 2020.

[23] G. Kress, Multimodality. A Social Semiotic Approach to Contemporary Communication. London: Routledge, 2010.

[24] L. Vygotskij, Mind in Society: The Development of Higher Psycological Processes. Cambridge, Mass: Harvard University Press, 1978.

[25] M. W. Wartofsky, Models. Representation and Scientific Understanding. Dordrecht: Reidel Publishing Company, 1979.

[26] T. Bratteteig, "A matter of digital materiality," in Exploring Design. Multi-disciplinary Designs Practices (I. Wagner, T. Bratteteig, and D. Stuedahl, eds.), pp. 147-170, New York: Springer, 2010.

[27] S. Hansson, "Defining technical function," Studies in History and Philosophy of Science, vol. 37, pp. 19-22, 2006.

[28] P. Vermaas and W. Houkes, "Technical functions: a drawbridge between the intentional and structural natures of technical artefacts," Studies in History and Philosophy of Science, vol. 37, pp. 5-18, 2006.

[29] P. Bøgh Andersen, A Theory of Computer Semiotics. Cambridge, UK: Cambridge University Press, 1997.

[30] J. Bezemer and G. Kress, Multimodality, Learning and Communication a Social Semiotic Frame. London: Routledge, 2016.

[31] G. Kress, Literacy in the New Media Age. London: Routledge, 2010.

[32] G. Kress, C. Jewitt, J. Ogborn, and C. Tsatsarelis, Multimodal Teaching and Learning, The Rhetorics of the Science Classroom. London: Bloomsbury, 2014.

[33] G. Kress and T. van Leeuwen, Multimodal Discourse: The Modes and Media of Contemporary Communication. London: Arnold, 2001.

[34] S. Norris and R. H. Jones, Discourse in Action. Introducing Mediated Discourse Analysis. Oxon: Routledge, 2005.

[35] C. Jewitt, Technology, Literacy and Learning. A Multimodal Approach. Oxon: Routledge, 2009.

[36] S. Selander and G. Kress, Design för lärande. Ett multimodalt perspektiv. Lund: Studentlitteratur, 2017.

[37] P. Aspers, Entografiska metoder. Stockholm: Liber, 2011.

[38] T. van Leeuwen, Introducing Social Semiotics. London: Routledge, 2005.

[39] S. Norris, Analyzing Multimodal Interaction: A Methodological Framework. London: Routledge, 2014.

[40] C. Jewitt, "Editorial," International Journal of Social Research Methodology, vol. 14, no. 3, pp. 171178, 2011.

[41] C. Jewitt, "An introduction to using video for research," NCRM Working Paper 03/12, London: Institute of Education, 2012.

[42] D. Shaffer, Quantitative Ethnography. Cathcart Press, 2017. 
[43] P. Bell, "Content Analysis of Visual Images," in The Handbook of Visual Analysis (T. van Leeuwen and C. Jewitt, eds), pp. 10-34, London: SAGE Publications Ltd, 2011.

[44] B. Eagan, J. Brohinsky, J. Wang, and D. Shaffer, "Testing the reliability of inter-rater reliability," in Proceedings of the Tenth International Conference on Learning Analytics \& Knowledge (LAK '20), pp. 454-46, New York: Association for Computing Machinery, 2020. doi:10.1145/3375462.3375508

[45] D. Shaffer, "Formatting data for epistemic network analysis, Technical report 2014-1," Games and Professional Simulations (GAPS), vol. 14, no. 1, 2014.

[46] X. Ochoa, "Mutlimodal learning analytics," in Handbook of Learning Analytics SOLAR, Society for Learning Analytics and Research (C. Lang, G. Siemens, A. Wise, and D. Gasevic, eds.), pp. 129141, 2017. Retrieved from https://solaresearch.org/hla-17/

[47] D. Spikol, E. Ruffaldi, and M. Cukurova, "Using multimodal learning analytics to identify aspects of collaboration in project-based learning," in Proceedings of the 12th International Conference on Computer Supported Collaborative Learning - Making a Difference: Prioritizing Equity and Access in CSCL (B. K. Smith, M. Borge, E. Mercier, and K. Y. Lim, eds.), pp. 263-270, Philadelphia: International Society of the Learning Sciences, 2017. 